\title{
Island Activities Detected by VIIRS and Validation with AIS
}

\section{Ichio Asanuma, Daisuke Hasegawa, Takashi Yamaguchi, Jong Geol Park, Kenneth James Mackin}

Department of Informatics, Tokyo University of Information Sciences, Chiba, Japan

Email: asanuma@rsch.tuis.ac.jp

How to cite this paper: Asanuma, I., Hasegawa, D., Yamaguchi, T., Park, J.G. and Mackin, K.J. (2018) Island Activities Detected by VIIRS and Validation with AIS. Advances in Remote Sensing, 7, 171-182. https://doi.org/10.4236/ars.2018.73012

Received: August 8, 2018

Accepted: September 8, 2018

Published: September 11, 2018

Copyright $\odot 2018$ by authors and Scientific Research Publishing Inc. This work is licensed under the Creative Commons Attribution International License (CC BY 4.0).

http://creativecommons.org/licenses/by/4.0/

\section{cc) (i) Open Access}

\begin{abstract}
A possibility to monitor the reclamation activities by remote sensing was discussed. The lights observed in the night time by Day Night Band (DNB) of Visible Infrared Imaging Radiometer Suite (VIIRS), ocean color observed in the day time by visible bands of VIIRS were the tools to monitor the surface activities, and the Automated Information System (AIS) was used to verify the types and number of vessels associated with the reclamation activities. The lights as the radiance from the surface were monitored by the object based analysis, where the object was defined as a radius of $5 \mathrm{~km}$ from the center of the Mischief Reef in the South China Sea (SCS). The time history of surface lights exhibited the increase of the radiance from January to May 2015 and the radiance was kept in the certain level to December 2016 with some variations. The ocean color, chlorophyll-a concentration as a proxy of sediments, showed an increase from February to June 2015 and returned to a low concentration in August 2015. According to the historical data of AIS, the number of dredgers has increased from February to August 2015 and the maximum number of dredgers was recorded in June 2015. The timing of increase of lights from surface, increase of chlorophyll-a concentration, and increase of number of vessels are consistent.
\end{abstract}

\section{Keywords}

Dredging, Reclamation, VIIRS, DNB, Chlorophyll-a, AIS

\section{Introduction}

The South China Sea (SCS) is the second largest semi-enclosed sea in the world and hosts a large marine ecosystem with the terrestrial inputs from rivers [1] [2] [3]. The SCS Basin in the north-east half extends the maximum depth to $5000 \mathrm{~m}$ (Figure 1). The continental shelf less than $200 \mathrm{~m}$ covers the major southern half 


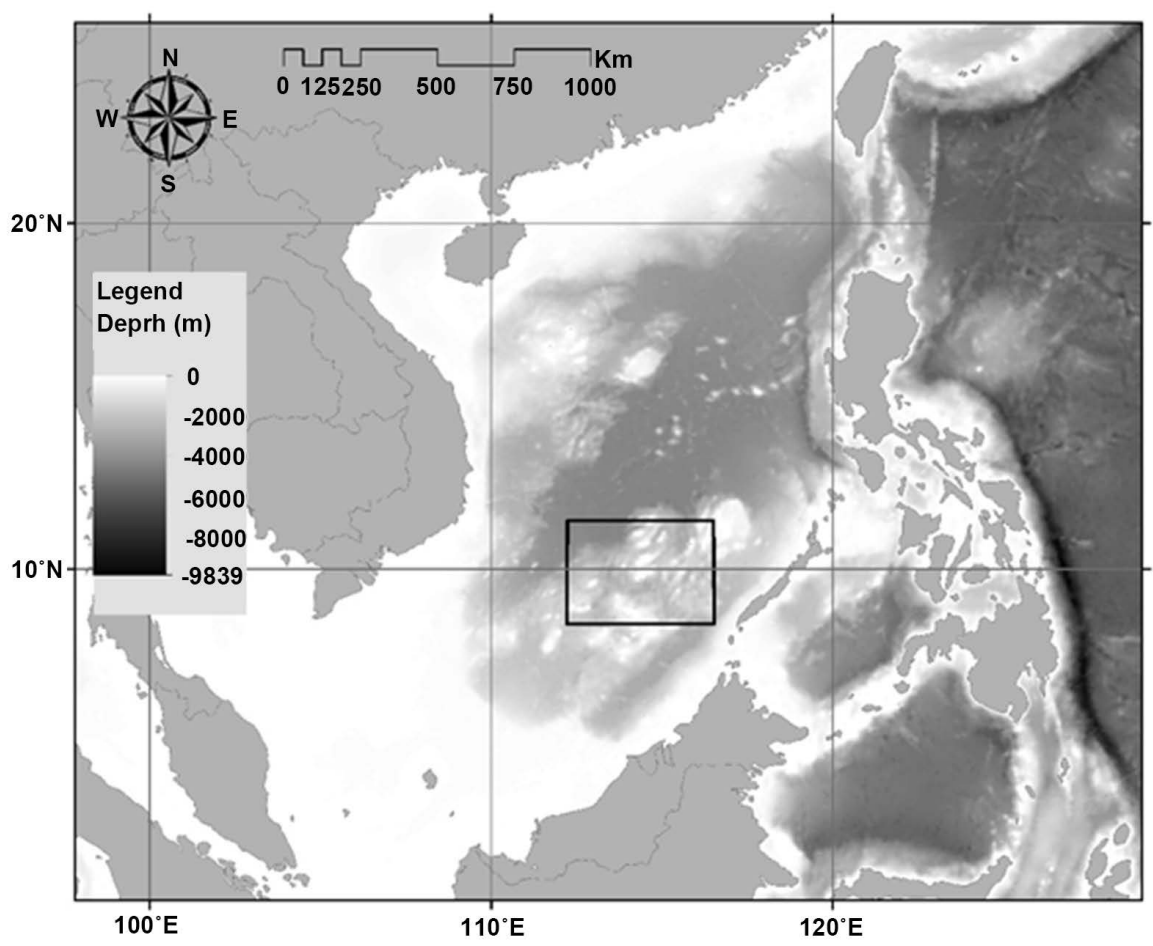

Figure 1. Bathymetry map of South China Sea, where the study area is indicated by a rectangle. Bathymetry map was generated from the bathymetry data of NASA SeaDAS.

of the SCS, along the coast of China, Vietnam, and the archipelagoes of Philippine, Malaysia and Indonesia. The SCS region is rich in both renewal fisheries resources, particularly pelagic resources, and hydrocarbon resources [4] [5]. The waters on the SCS could be classified into two regions including the coastal water and potential transboundary for fisheries. The SCS provides the surface routes between the Far East and the Middle East because of its geographical location as the International Sea Lane to transport petroleum resources and commercial products vice versa [6]. More than half of the world's commerce is traveled by sea and about half of the world's oil tanker shipments pass through its water [7]. Spratly Islands on SCS were proclaimed for an entire or partial ownership by China and some countries [8] [9] [10] [11]. China built artificial islands with a total area of close to 3000 acres on seven coral reefs in the Spratly Islands from December 2013 to October 2015 [12]. The dredging and filling operations over the reef systems have raised concerns over potential damage to important ecosystems and associated fisheries [11] [12] [13]. Recently available remote sensing data, i.e., Landsat-8 Operational Land Imager and Thermal Infrared Sensors Terrain Corrected images, allow quantification of the sharp contrast between the gain of land and the loss of coral reefs resulting from reclamation in the Spratly Islands [14]. According to Asia Maritime Transparency Initiative (AMTI), the first dredger was observed at the Mischief Reef on January 25, 2015 [15]. Dredging and deposition operations continued until the middle of 2015. Aerial photography showed the last dredgers on June 10, 2015, at which 
point the final coastal line bounded 1367 acres $\left(5.53 \mathrm{~km}^{2}\right)$ of reclaimed island [15] [16]. The buildings and a 3000-meter runway were then constructed. A civilian plane landed on Mischief Reef for the first time on July 12, 2016, the same day as the first landing on Subi Reef [16].

The Day Night Band (DNB) of Visible Infrared Imaging Radiometer Suite (VIIRS) on Suomi-National Partnership Program (S-NPP) provides a panchromatic image of the surface in the night, integrating from 500 to $900 \mathrm{~nm}$ [17]. The DNB is operated with three gains and the vicarious calibrations have been reported to keep a consistent use of data [18] [19]. The radiance observed by DNB is in the range of the minimum radiance of $3 \mathrm{nW} \cdot \mathrm{cm}^{-2} \cdot \mathrm{sr}^{-1}$, which is a sufficient signal to noise ratio, and to the maximum radiance of $100 \mathrm{nW} \cdot \mathrm{cm}^{-2} \cdot \mathrm{sr}^{-1}$, which is the saturation level of DNB [20]. At night, the DNB maintains a nearly constant pixel foot print of $742 \mathrm{~m}$, where the subpixels are aggregated in both the scan and track directions according to a complex scheme to achieve the near constant resolution of 742 by 742 meters across scan and along track [20] [21]. As the spatial footprint of the DNB is large enough that several boats could be present in a single pixel, a validation effort would be required to define the types of boats that are detected in terms of the installed wattage of lighting, lighting types, shielding present on the lights and orientation of the lights while in operation [21]. The DNB has a wide variety of applications from this optical property [22]. The DNB data were applied to the analysis of urban activities from street lights [17] [20]-[25], the recognition of fishing boats from lights for fishing [21] [25] [26], and the metrological application with clouds distribution associated with fronts and typhoons [18] [25]. First two applications on urban and fishery lights are restricted by the moonlight reflected by clouds, but the last applications of cloud distribution needs the lunar lights which are available for $\sim 1 / 2$ of the 29.5 day lunar cycle [25] [27].

Current ocean color sensors in space used for monitoring the biochemical properties of ocean water including Moderate Resolution Imaging Spectro-radiometer (MODIS) on Terra and Aqua are near the end of their lifetimes [28]. Ocean color remote sensing has entered a new phase with the successful deployment of VIIRS, and the characteristics of VIIRS are well-suited for ocean color radiometry applications such as oceanic algal biomass or coastal waters monitoring. The VIIRS has five spectral channels centered at 410,443, 486, 551 and $671 \mathrm{~nm}$ that are used to characterize spectral ocean color with additional channels for atmospheric correction, and realized to produce the ocean color products with level-2 generation algorithm [29] [30]. Most empirical ocean color algorithms to estimate the chlorophyll-a concentration have been developed primary for optically deep water [31], and are still difficult for coastal waters [32]. The turbid waters, defined as case 2 waters, exhibit optically complex constituents consisting primary of suspended sediment matter, colored dissolved organic matter and phytoplankton [32] [33]. Also, the water around the coral reef may have the bottom reflectance through shallow water. The algorithm of blue-to-green ratios 
of remote sensing reflectance can produce large biases in the chlorophyll-a estimate over the case 2 waters [32]. Because of the large biases, the chlorophyll-a concentrations estimated over the turbid water associated with dredging could be used as a proxy to present sediment concentration, although the quantitative data are not available.

The regulation 19 of the Safety of Life at Sea (SOLAS) requires the automatic identification system (AIS) to be fitted aboard all ships of 300 gross tonnage and upwards engaged on international voyages, cargo ships of 500 gross tonnage and upwards not engaged on international voyages and all passenger ships irrespective of size [34] [35]. E-Navigation is conceived to improve the traditional traffic management instruments and measures by enhancing berth to berth navigation and related services for safety and security at sea and protection of the marine environment [36]. AIS data is possible to detect anomalies, being caused by illegal actions, such as smuggling, pollution, and unauthorized fishing, and or piracy application [36] [37] [38]. Two approaches have been reported to detect anomalies by the grid-based approaches and the methods using vectorial representation of traffic [36]. Unfortunately, AIS data transferred and received can be manipulated or hindered with a limited trustworthiness due to the fact that every vessel owner can manipulate the system or can completely turn it off [39] [40].

DNB on VIIRS provided a new era to observe the lights from the surface in the night-time and in the real-time. The DNB is a good tool to monitor the anthropogenic activities on the remotely located ocean. As the reclamation activities on SCS were the significant concerns for countries facing to SCS, a possibility of remote sensing by DNB, as a change of light intensity from the surface, and by the chlorophyll-a concentration, as a proxy of sediment concentration associated with the dredging activities, were examined. Those two remotely monitored parameters were validated with the AIS data, which report the number of vessels with its name, type, and other related information.

\section{Data and Method}

\subsection{Objective Analysis of DNB}

VIIRS data were received at the receiving station located on the Miyakojima Island, Japan, which has a coverage to the central part of SCS. The received data were processed to level- 0,1 , and 2 by the International Polar Orbiter Processing Package (IPOPP) provided by the Direct Readout Laboratory of NASA. DNB data were extracted from the Geolocation data for DNB and Sensor data record of VIIRS for DNB. DNB data were mapped over the region of interest using the HDF to TiFF function of IPOPP. Radiance of DNB from 0.0 to $100.0 \mathrm{nW} \cdot \mathrm{cm}^{-2} \cdot \mathrm{sr}^{-1}$ is recorded on the GeoTiFF data.

The series of GeoTiFF data of DNB are opened on ArcMAP for the scale variable objective analysis based on the size of anthropogenic activities on the coral reefs in the SCS, as the point based analysis didn't work to detect the temporal 
change of activities. The Mischief Reef was selected to study the possibility of analyzing the temporal changes of activities within the coral reef and including waters around the reef. The object size of the Mischief Reef was defined as a radius of $5 \mathrm{~km}$ from the center of reef.

\subsection{Chlorophyll-a Concentration as a Proxy of Sediment Concentration}

Chlorophyll-a concentration is also derived from the observation by the visible bands of VIIRS over SCS using the level-2 generation function of IPOPP, and the region of interest is projected into GeoTiFF data by IPOPP. The level-2 generation algorithm was extracted from the Ocean Biology Processing Group's Sea-viewing Wide Field-of-View Sensor (SeaWiFS) Data Analysis System and produces VIIRS Ocean Color, chlorophyll-a concentration, from inputs of VIIRS Sensor Data Record products, the VIIRS Moderate Resolution Terrain Corrected Geolocation products and optional ancillaries [30]. The level-2 generation function is provided to the direct receiving stations from the Direct Readout Laboratory of NASA for the real-time processing. Chlorophyll-a concentration from 0.01 to $100.0 \mathrm{mg} \cdot \mathrm{m}^{-3}$ is recorded on the GeoTiFF data. As it is difficult to analyze the chlorophyll-a concentration using the daily observation or the weekly composite due to the frequent presentation of clouds in this region, the monthly composite data were generated for the temporal analysis.

The series of GeoTiFF data of chlorophyll-a concentration are opened on ArcMAP for the scale variable objective analysis as well as DNB analysis. The object size was determined as a radius of $5 \mathrm{~km}$ from the center of reef.

\subsection{Historic Data of AIS}

The historic data of AIS over SCS from December 2014 to August 2015 with an interval of 5 days were purchased. Each AIS data are opened on ArcMAP and the data included within the region of interest was clipped, which is defined within a diameter of $5 \mathrm{~km}$ from the center of the coral reef. The clipped data was transformed into the excel format with a function to convert from the table to excel so as to identify the Maritime Mobile Service Identity (MMSI), ship category, and gross tone.

\section{Result and Discussion}

\subsection{Temporal Change of DNB and Ocean Color}

Figure 2 shows a temporal change of DNB on the left side and Chlorophyll-a concentration from January to August 2015 on the right side. DNB is the observation on a specific date, where the radiance between 0 and $100 \mathrm{nW} \cdot \mathrm{m}^{-2} \cdot \mathrm{sr}^{-1}$ is displayed from black to white. Chlorophyll-a concentration is the monthly composite from December 2014 to August 2015, where chlorophyll-a concentration between 0.01 and $2.0 \mathrm{mg} \cdot \mathrm{m}^{-3}$ is colored from blue to red. DNB on Jan. 18, 2015 (Figure 2(a)) shows a single spot on the South West end of the Mischief 

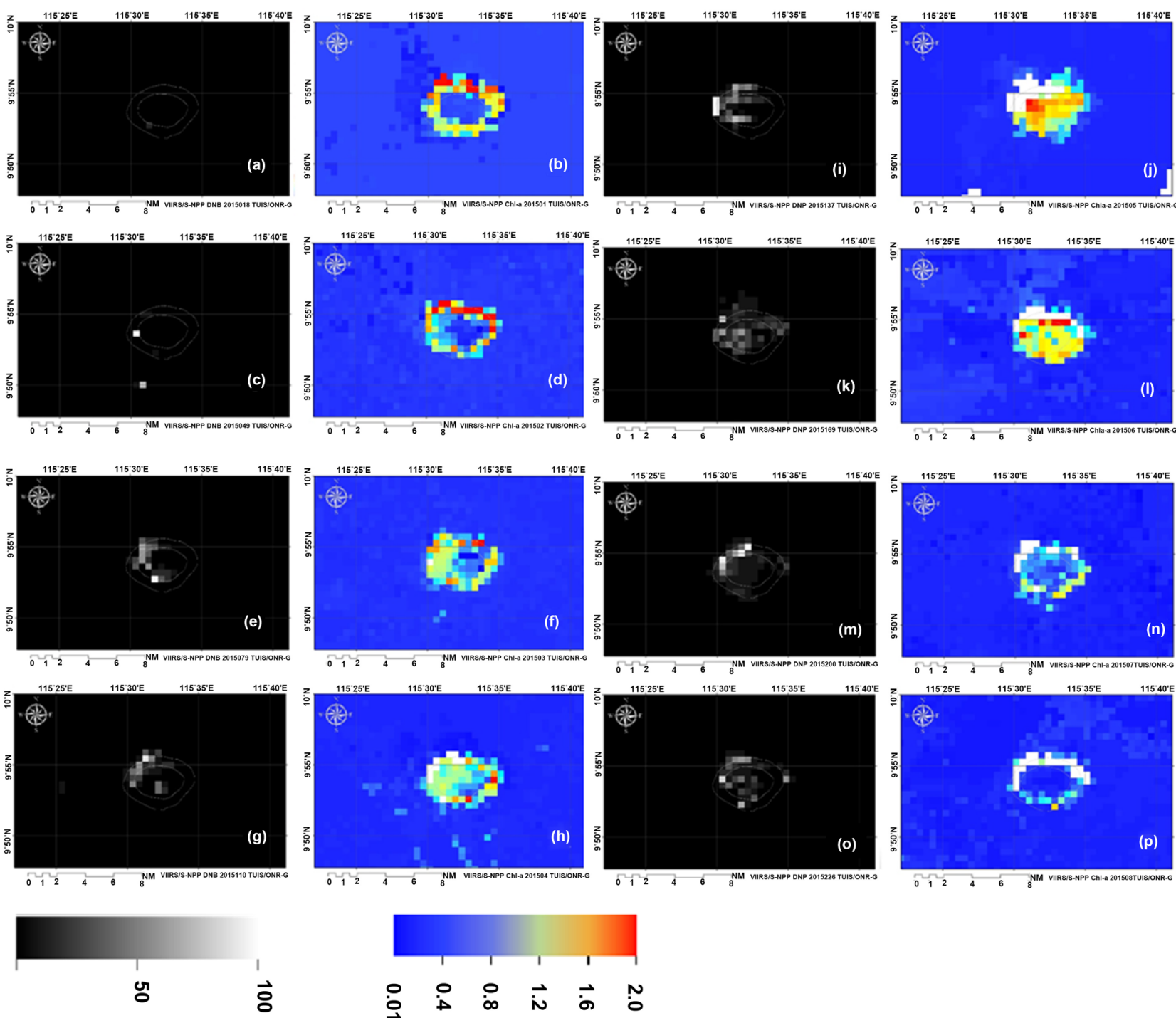

DNB Radiance $\left(\mathrm{nW} \cdot \mathrm{m}^{-2} \cdot \mathrm{sr}^{-1}\right)$

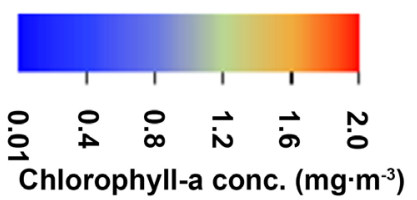

Figure 2. Temporal change of DNB and Chlorophyll-a concentration around the Mischief Reef. Left side is the distribution of surface lights observed by DNB of VIIRS on the specific date, January 18 (a), February 18 (c), March 20 (e), April 20 (g), May 17 (i), June $18(\mathrm{k})$, July $19(\mathrm{~m})$ and August 14 (o), 2015. Right side is the distribution of Chlorophyll-a concentration observed by the visible band of VIIRS in January (b), February (d), March (f), April (h), May (j), June (l), July (n), and August (p), 2015.

Reef and Chlorophyll-a concentration in January 2015 (Figure 2(b)) showed a higher concentration along the reef. DNB on Feb. 18 (Figure 2(c)) showed a high intensity within and outside of the reef and Chlorophyll-a concentration in February 2015 (Figure 2(d)) showed a higher concentration within the reef. DNB on Mar. 20 (Figure 2(e)) showed numbers of lights along and within the reef and Chlorophyll-a concentration in March 2015 (Figure 2(f)) showed a higher concentration within the reef. DNB on Apr. 20 (Figure 2(g)) showed the lights moved to the north and Chlorophyll-a concentration in April 2015 (Figure 2(h)) also showed a higher concentration within the reef. DNB on May 17 (Figure 2(i)) showed a distribution of lights on the west side of the reef and Chlorophyll-a concentration in May (Figure 2(j)) showed the highest concen- 
tration within the reef and some around the reef. DNB on June 18 (Figure 2(k)) showed a wide distribution within and outside of the reef and Chlorophyll-a concentration in June (Figure 2(1)) also showed the high concentration within the reef as well as in May. DNB on July 19 (Figure 2(m)) showed the lights are concentrated on the north-west side of the reef and Chlorophyll-a concentration in July (Figure 2(n)) exhibited a decrease in concentration within the reef. DNB on Aug. 14 (Figure 2(o)) showed the lights are scattered within the reef but Chlorophyll-a concentration in August (Figure 2(p)) showed a very low concentration within the reef as well as January 2015.

Figure 3 is the temporal change of the radiance from the surface observed by DNB and Chlorophyll-a concentration observed by visible bands of VIIRS. The radiance and concentration are given as the mean value within the object, defined as a radius of $5 \mathrm{~km}$ from the center of the Mischief Reef. The radiance observed by DNB (filled circle) on Figure 3 showed the lowest level from January 2014 to January 2015 and showed the increase from February to May and the higher radiance continued to December 2016 with some variations. The mean Chlorophyll-a concentration by visible band (outlined square) on Figure 3 showed the increase from January to May and June 2015 as well as the increase of the radiance observed by DNB, and decreased to August 2015.

The profile of the radiance observed by DNB indicates that dredging activities started from January 2015, but it is difficult to identify the timing when the dredging had terminated. In contrast, the profile of Chlorophyll-a concentration indicates that the dredging activities started from January 2015 and terminated by July judging from the decrease of suspended particles associated with the dredging activities and the clear water was returned in August 2015

\subsection{AIS Records}

Figure 4 shows the classified results of vessels by types and MMSI within the region of interest of the Mischief Reef within a diameter of $5 \mathrm{~km}$ from the center of the reef. The types of vessels are classified to tug and supply, dredger, cargo,

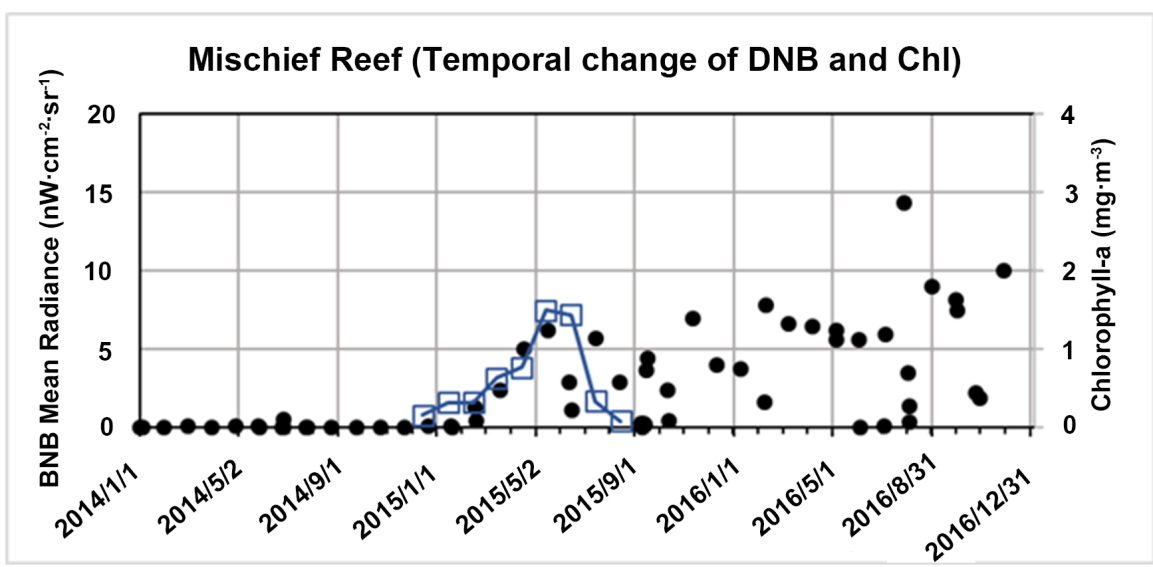

Figure 3. Temporal change of DNB (filled circle) from January 1, 2014 to December 31, 2016, and Chlorophyll-a concentration (outlined square) from January to August 2015. 


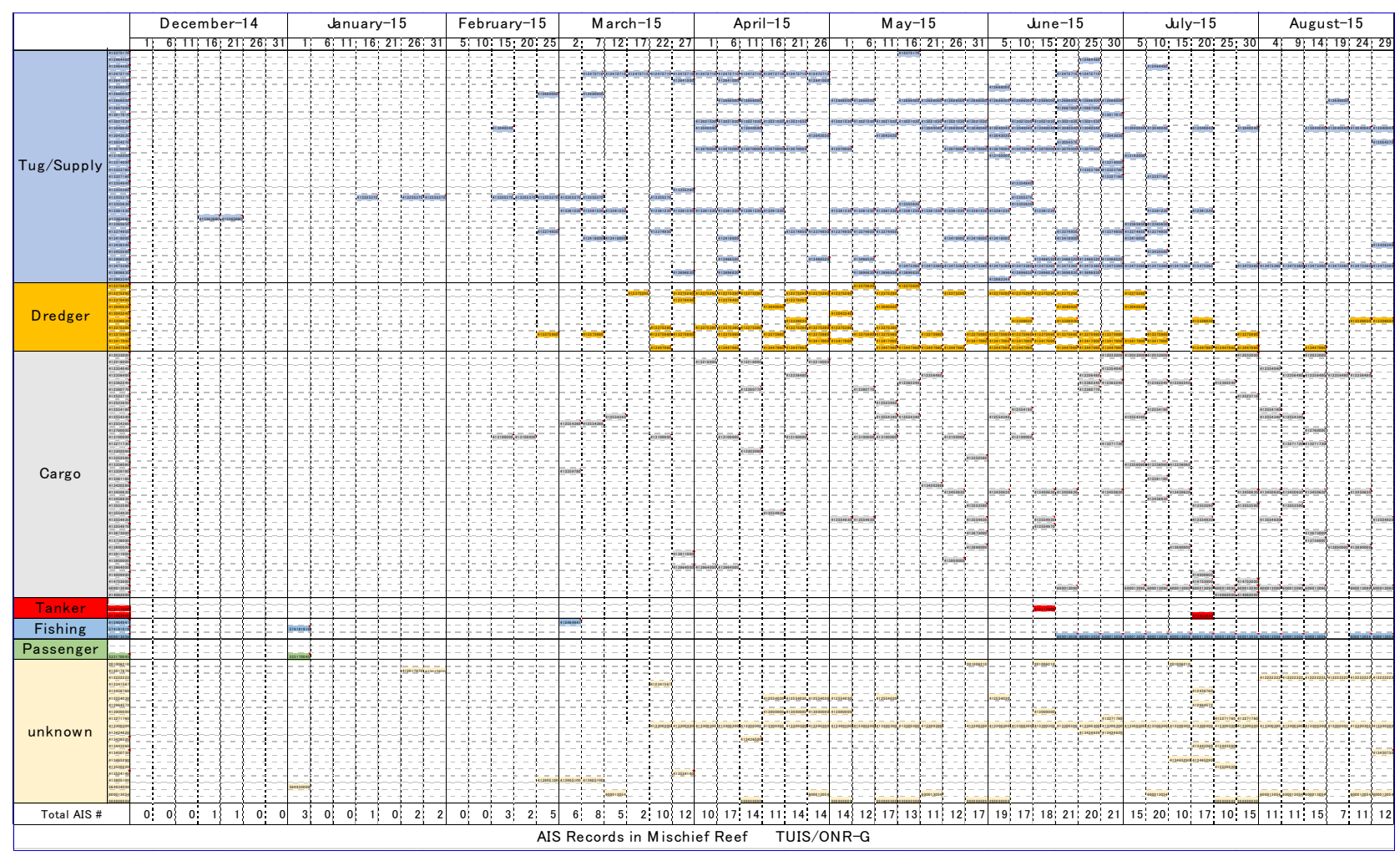

Figure 4. Classification of AIS record within a buffer of Mischief Reef by types of vessels and by MMSI from December 2014 to August 2015.

tanker, fishing boat, passenger boat, and unknown. Each line is corresponding to one MMSI through the period from December 2014 to August 2015. One tug boat was recorded on December 16 and 21, 2014. On January $1^{\text {st }}, 2015$, one fishing boat, one passenger boat and unknown vessel were recorded within the Mischief Reef. In the Mischief Reef, the passenger boat was the first time and the last time recorded on AIS in this period. The number of vessels was very small from the middle of December 2014 to February 2015. The number of vessels recorded 5 and increased since February 25, 2015 including dredgers and others. The maximum number of vessels was recorded 21 on June 20,2015. The period of high chlorophyll-a concentration was from March to June 2015 as indicated on Figure 2 and Figure 3, and the period is corresponding to the period while the big number of dredgers was recorded on AIS.

AIS exhibited the intermittent records for all most of vessels, some of them might be conducting frequent visits from and to the Mischief Reef or there was a possibility some of their AIS being turned off. From the middle of June 2015, two tankers visited and one fishing boat stayed in the Mischief Reef. Some of AIS records showed only MMSI but its name or types are unknown, but those unknown vessels might have a contribution to the reclamation activities.

\subsection{Dredging Period Validated by AIS}

The dredging and reclamation activities on SCS was monitored using the lights 
from the surface observed in the night time by DNB of VIIRS, ocean color observed in the day time by visible bands of VIIRS, and were validated by the types of vessels of AIS record. The lights as the radiance from the surface were monitored and the object based analysis was executed, where the object was defined as a radius of $5 \mathrm{~km}$ from the center of the Mischief Island. The time history of surface lights exhibited the increase of the radiance from January to May 2015 and the radiance was kept in the certain level to December 2015 with some variations. The dredging period was not identified only from the lights from the surface. The ocean color, chlorophyll-a concentration as a proxy of sediments, showed an increase from February to June 2015 and returned a clear water in August 2015, which could be corresponding to the dredging period. According to the historical data of AIS, the number of dredgers has increased from February to August 2015 and the maximum number of dredgers was recorded in June 2015. The timing of increase of lights from surface, increase of chlorophyll-a concentration, and increase of number of vessels were consistent among them. The dredging activities started in February 2015, while the first dredger was recorded on AIS. The termination of dredging activities could be estimated from the decrease of chlorophyll-a concentration from June to July 2015, while the number of dredgers decreased in July 2015. The AIS data exhibited the intermittent data distribution in time sequence which might be caused by the AIS equipment on board being turned off, but the AIS data supported the validation of remote sensing data. It was confirmed that AIS record are very useful for the validation of remote sensing data analysis.

\section{Conclusion}

DNB is able to detect the lights from the surface regardless the size of light source with the sufficient intensity within each pixel. The objective analysis made it possible to identify the temporal change of the light history associated with the anthropogenic activities over the coral reef, although it was difficult to monitor the temporal change by pixel base analysis due to moving vessels. The chlorophyll-a concentration as a proxy of sediments detected the temporal change of ocean color associated with the dredging activities. The combination of two different types of observations made it possible to confirm the dredging activities. Finally, it is possible to estimate that the dredging activities were conducted from February to June 2015, of which period was validated with AIS records. The reclamation activities might have continued to December 2016 judging from the surface lights over the Mischief Reef, which kept the certain level in radiance including lights from the associated supporting vessels and the land activities.

\section{Acknowledgements}

This research is partly supported by the Office of Naval Research Global of the USA with the grant number of N62909-15-1-2074. 


\section{Conflicts of Interest}

The authors declare no conflicts of interest regarding the publication of this paper.

\section{References}

[1] Dang, T.N. (2012) Fisheries Cooperation in the South China Sea and the (Ir)relevance of the Sovereignty Question. Asian Journal of International Law, 2, 59-88. https://ssrn.com/abstract=1871314 https://doi.org/10.1017/S2044251311000099

[2] Pomeroy, R.S. (2012) Managing Overcapacity in Small-Scall Fisheries in Southeast Asia. Marine Policy, 36, 520-527. https://doi.org/10.1016/j.marpol.2011.10.002

[3] Witter, A., The, L., Yin, X., Ccheung, W.W.L. and Sumaila, U.R. (2015) Taking Stock and Projecting the Future of South China Sea Fisheries. Working Paper \#2015-99. The University of British Columbia, Vancouver.

[4] Yu, N.J. (1998) South China Sea. National Geographic, 194, 3-33.

[5] Khemakorn, P. (2006) Sustainable Management of Pelagic Fisheries in the South China Sea Region. United Nations, New York.

[6] Rosenberg, D. (1999) Environmental Pollution around the South China Sea: Developing a Regional Response. Contemporary Southeast Asia, 21, 119-145.

https://www.jstor.org/stable/25798444 https://doi.org/10.1355/CS21-1F

[7] Bader, J., Lieberthal, K. and McDevitt, M. (2014) Keeping the South China Sea in Perspective. The Foreign Policy Brief. Brookings, Washington DC, 1-11.

[8] Velasco, M.A.M. (2014) Philippines-China Relations: The Case of South China Sea (Spratly Islands) Claims. Asia Pacific Journal of Multidisciplinary Research, 2, 78-85.

[9] Gewirtz, P. (2016) Limits of Law in the South China Sea. East Asia Policy Paper. Brookings, Washington DC, 1-17.

[10] Herscovitch, B. (2017) A Balanced Threat Assessment of China's South China Sea Policy. Policy Analysis. CATO Institute, Washington DC, 1-28.

[11] Asner, G.P., Martin, R.E. and Mascaro, J. (2017) Coral Reef Atoll Assessment in the South China Sea Using Planet Dove Satellites. Remote Sensing in Ecology and Conservation, 3, 57-65. https://doi.org/10.1002/rse2.42

[12] Southerland, M. (2016) China's Island Building in the South China Sea: Damage to the Marine Environment, Implications, and International Law, U.S.-China Economic and Security Review Commission. Staff Research Report, 11 p.

[13] McManus, J.W. (2017) Offshore Coral Reef Damage, Overfishing, and Paths to Pease in the South China Sea. The International Journal of Marine and Coastal Law, 32, 199-237. https://doi.org/10.1163/15718085-12341433

[14] Mora, C., Caldwell, I.R., Birkeland, C. and McManus, J.W. (2016) Dredging in the Spratly Islands: Gaining Land but Losing Reefs. PLOS Biology, 14, 1-7. https://doi.org/10.1371/journal.pbio.1002422

[15] AMTI (2018) Fiery Cross Reef Tracker, Asia Maritime Transparency Initiative. https://amti.csis.org/fiery-cross-reef/

[16] Macias, A. (2016) This Is What the Next Flash Point in the South China Sea Looks Like. Business Insider.

https://www.businessinsider.com/mischief-reef-flashpoint-south-china-sea-2016-8 
[17] Kyba, C.C.M., Garz, S., Kuechly, H., de Miguel, A.S., Zamorano, J., Fischer, J. and Hölker, F. (2015) High-Resolution Imagery of Earth at Night: New Sources, Opportunities and Challenges. Remote Sensing, 7, 1-23. https://doi.org/10.3390/rs70100001

[18] Ma, S., Yan, W., Huang, Y., Ai, W. and Zhao, X. (2015) Vicarious Calibration of S-NPP/VIIRS Day-Night Band Using Deep Convective Clouds. Remote Sensing of Environment, 158, 42-55. https://doi.org/10.1016/j.rse.2014.11.006

[19] Liu, Q. and Boukabara, S. (2014) Community Radiative Transfer Model (CRTM) Applications in Supporting the Suomi National Polar-Orbiting Partnership (SNPP) Mission Validation and Verification. Remote Sensing of Environment, 140, 744-754. https://doi.org/10.1016/j.rse.2013.10.011

[20] Cao, C. and Bai, Y. (2014) Quantitative Analysis of VIIRS DNB Nightlight Point Source for Light Power Estimation and Stability Monitoring. Remote Sensing, 6, 11915-11935. https://doi.org/10.3390/rs61211915

[21] Elvidge, C.D., Zhizhin, M., Baugh, K. and Hsu, F. (2015) Automatic Boat Identification System for VIIRS Low Light Imaging Data. Remote Sensing, 7, 3020-3036. https://doi.org/10.3390/rs70303020

[22] Mazor, T., Levin, N., Possingham, H.P., Levy, Y., Rocchini, D. and Richardson, A.J. (2013) Can Satellite-Based Night Lights Be Used for Conservation? The Case of Nesting Sea Turtles in the Mediterranean. Biological Conservation, 159, 63-72. https://doi.org/10.1016/j.biocon.2012.11.004

[23] Levin, N. and Duke, Y. (2012) High Spatial Resolution Night-Time Light Images for Demographic and Socio-Economic Studies. Remote Sensing of Environment, 119, 1-10. https://doi.org/10.1016/j.rse.2011.12.005

[24] Zhang, Q., Schaaf, C. and Seto, K.C. (2013) The Vegetation Adjusted NTL Urban Index: A New Approach to Reduce Saturation and Increase Variation in Nighttime Luminosity. Remote Sensing of Environment, 129, 32-41. https://doi.org/10.1016/j.rse.2012.10.022

[25] Miller, S.D., Straka, W., Mills, S.P., Elvidge, C.D., Lee, T.F., Solbrig, J., Walther, A., Heidinger, A.K. and Weiss, S.C. (2013) Illuminating the Capabilities of the Suomi National Polar-Orbiting Partnership (NPP) Visible Infrared Imaging Radiometer Suite (VIIRS) Day/Night Band. Remote Sensing, 5, 6717-6766. https://doi.org/10.3390/rs5126717

[26] Straka, W.C., Seaman, C., Baugh, K., Cole, K., Stevens, E. and Miller, S.D. (2015) Utilization of the Suomi National Polar-Orbiting Partnership (NPP) Visible Infrared Imaging Radiometer Suite (VIIRS) Day/Night Band for Arctic Ship Tracking and Fisheries Management. Remote Sensing, 7, 971-989.

https://doi.org/10.3390/rs70100971

[27] Johnson, R.S., Zhang, J., Hyer, E.J., Miller, S.D. and Reid, J.S. (2013) Preliminary Investigations toward Nighttime Aerosol Optical Depth Retrievals from the VIIRS Day/Night Band. Atmospheric Measurement Techniques, 6, 1245-1255. https://doi.org/10.5194/amt-6-1245-2013

[28] Hlaing, S., Harmel, T., Gilerson, A., Foster, R., Weidemann, A., Arnone, R., Wang, M. and Ahmed, S. (2013) Evaluation of the VIIRS Ocean Color Monitoring Performance in Coastal Region. Remote Sensing of Environment, 139, 398-414. https://doi.org/10.1016/j.rse.2013.08.013

[29] Davis, C.O., Tufillaro, N., Nahorniak, J., Jones, B. and Arnone, R. (2013) Evaluating VIIRS Ocean Color Products for West Coast and Hawaiian Waters. Proceedings of SPIE, 8724, 87240J. https://doi.org/10.1117/12.2016177 
[30] NASA (2016) L2GEN Science Processing Algorithm (L2GEN_SPA). User's Guide, $17 \mathrm{p}$.

[31] Cannizzaro, J.P. and Carder, K.L. (2006) Estimating Chlorophyll a Concentrations from Remote-Sensing Reflectance in Optically Shallow Waters. Remote Sensing of Environment, 101, 13-24. https://doi.org/10.1016/j.rse.2005.12.002

[32] Shen, F., Zhou, Y.-X., Li, D.-J., Zhu, W.-J. and Salama, M.S. (2010) Medium Resolution Imaging Spectrometer (MERIS) Estimation of Chlorophyll-A Concentration in the Turbid Sediment-Laden Waters of the Changjiang (Yangtze) Estuary. International Journal of Remote Sensing, 31, 4635-4650. https://doi.org/10.1080/01431161.2010.485216

[33] Zhang, Y., Lin, H., Chen, C., Chen, L., Zhang, B. and Gitelson, A.A. (2011) Estimation of Chlorophyll-A Concentration in Estuarine Waters: Case Study of the Pearl River Estuary, South China Sea. Environmental Research Letters, 6, Article ID: 024016. http://iopscience.iop.org/article/10.1088/1748-9326/6/2/024016

[34] International Convention for Safety of Life at Sea (SOLAS) (2002) Chapter V: Safety of Navigation, Regulation 19, 13 December 2002.

[35] Ahlberg, E. and Danielsson, J. (2015) Handling and Analyzing Marine Traffic Data. Master of Science Thesis in the Programme Computer Science, Chalmers University of Technology, $75 \mathrm{p}$.

[36] Fiorini, M., Capata, A. and Bloisi, D.D. (2016) AIS Data Visualization for Maritime Spatial Planning (MSP). International Journal of e-Navigation and Maritime Economy, 5, 45-60.

[37] Martineau, E. and Roy, J. (2011) Maritime Anomaly Detection: Domain Introduction and Review of Selected Literature. Defence R\&D Canada, Valcartier, 26 p.

[38] Pallotta, G., Vespe, M. and Bryan, K. (2013) Vessel Pattern Knowledge Discovery from AIS Data: A Framework for Anomaly Detection and Route Prediction. Entropy, 15, 2218-2245. https://doi.org/10.3390/e15062218

[39] Brüggemann, S., Bereta, K., Xiao, G. and Koubarakis, M. (2016) Ontology-Based Data Access for Maritime Security. In: Sack, H., Blomqvist, E., d'Aquin, M., Ghidini, C., Ponzetto, S. and Lange, C., Eds., The Semantic Web. Latest Advances and New Domains, Lecture Notes in Computer Science, Vol. 9678, Springer, Cham, 741-757. https://doi.org/10.1007/978-3-319-34129-3_45

[40] Kanjir, U., Greidanus, H. and Ostir, K. (2018) Vessel Detection and Classification from Spaceborne Optical Images: A Literature Survey. Remote Sensing of Environment, 207, 1-26. https://doi.org/10.1016/j.rse.2017.12.033 